\title{
EVALUATION OF EFFECTS OF CORRECTIVE EXERCISES ON PES PLANOVALGUS IN PRESCHOOL CHILDREN

\author{
Miroslava Šutvajová ${ }^{1}$, Kristína Bul'áková ${ }^{2}$ Peter Bartík $^{3}$, Anna Lesňáková ${ }^{4}$,
} Zuzana Hudáková ${ }^{5}$
}

\begin{abstract}
:
Introduction: The foot forms the natural base of the human body bearing all its weight. Over the course of a person's life, the foot ensures the contact of the body with the terrain and creates the basic support during dynamic activities such as walking or running, especially on uneven terrain. (Véle, 2006)

Objectives: The aim of the research was to verify the effects of targeted corrective exercises on healthy foot development in preschool children.

Methods: The research was conducted from September 2018 to March 2019. The research sample consisted of 105 probands (59 preschool girls and 46 preschool boys), out of whom $7.62 \%$ had the physiological position of the arch on the right foot during baseline measurements. The average age of probands was 5 years. The measured parameters were the foot arch height without and with a load. Measurements were taken before and after rehabilitation intervention.

Results: The statistical analysis of the results confirmed the positive effect of rehabilitation treatment in all monitored variables on statistically significant diference in terms of an elevation in the foot arch $(p<0.005)$ and the influence of risk factors contributing to the development of researched foot deformities. The obtained data were processed into tables and graphs and subsequently evaluated.
\end{abstract}

Conclusion: Our study has shown that the most effective is the active exercise strengthening. The affected muscles maintain the foot arch as well as the whole posture.

UDC Classification: 615.8, DOI: https://doi.org/10.12955/pmp.v1.107

Keywords: Flat Foot, Children, Sensorimotor Stimulation.

\section{Introduction}

One of the main reasons why parents bring their children to the orthopedics is the three-dimensional deformity of the foot that occurs during the initial period of their growth. It consists of two obvious components. The first is the collapse of the medial longitudinal arch and the second is the elevated valgosity of the heel (Halabchi et al, 2013).

\section{Flat Feet in Children - Pes Planovalgus}

The plantar arch is a structure that keeps all parts of the foot (joints, ligaments and muscles) united. Due to its changes, curvature and elasticity it can normally adapt itself to unevenness in the terrain and can transmit forces caused by body weight and movements. The arch also serves as a shock absorber in flexible walking. Any pathology that flattens or increases the foot curvature therefore, seriously influences supporting our body while walking, running and keeping upright posture (Kapandji 2009). The plantar arch consists of three vaults that lie in three imaginary points creating an equilateral triangle on a surface. The arches form a spatial vault in the transverse and longitudinal directions. The three apparent arches (lateral, medial and transverse) define the vault, converging into three pillars which touch a surface in the place of the first and fifth metatarsal heads and in the dorsal part of the heel and so the vault can transmit the applied load on the pillars (Vařeka, Vařeková 2009). The key point of the foot arch is its highest upper part - the talus bone. It connects the foot to the lower leg through a joint with the distal bone of the tibia and the fibula (talocrural joint). It is precisely positioned because it has no muscular connections; therefore its stability depends on the ligaments surrounding it as well as the external and internal muscles (Moore et al. 2019) Both passive and active factors contribute to maintaining the longitudinal and transverse arches of the foot. Passive factors include the overall shape of the foot, the arrangement of individual bones and the ligaments. Muscles are active factors. The weight of the human body is transmitted by the back of the leg at the level of the ankle joint. The forces

\footnotetext{
${ }^{1}$ Faculty of Health, Catholic University in Ružomberok, Slovakia, ferancova.mirka@ gmail.com

${ }^{2}$ Faculty of Health, Catholic University in Ružomberok, Slovakia, kristina.bulakova@gmail.com

${ }^{3}$ Faculty of Health, Catholic University in Ružomberok, Slovakia, pbartik@psu.edu.sa

${ }^{4}$ Central Military Hospital SNU-FH Ružomberok and Faculty of Health, Catholic University in Ružomberok,

Slovakia, anna.lesnakova@ku.sk

${ }^{5}$ Faculty of Health, Catholic University in Ružomberok, Slovakia, zuzana.hudakova@ku.sk

Correspondence should be addressed to Kristína Bul'aková, kristina.bulakova@gmail.com
} 
induced by the load are then distributed from this point to the three abovementioned points of support. When the body is motionless in an upright position, 50 percent of the weight is transmitted to the calcaneus and 50 percent to the metatarsal heads, with the first metatarsal head absorbing twice as much force as the others. The same is true of the medial arch, which takes up about two-thirds of the total weight, while the lateral arch takes up only one-third. Under load, the medial and lateral arches are flattened, the head of the talus and lateral hump shift resulting in torsion in the Chopart's joint, the axis of the posterior leg is shifted medially, while the axis of the anterior leg is shifted laterally. The posterior leg rotates in transition into adulthood, in the verbal plane into adduction, pronation and slight elongation, while the anterior leg rotates into extension, abduction and supination relative to the posterior leg (Vařeka, Vařeková 2009).

\section{Ontogenesis}

At the end of the first year of life, when the first contact of the foot with the surface happens, the arch, which already becomesnoticeable, gets flattened because the body load is shifted to the thumb and even due to a slight weakening of the supporting ligaments, the forefoot is pronounced and the back of the foot drops into valgosity. The heel valgosity is reinforced by the physiological position of genua valga while the standard is given to an angle of about 15 degrees. Thus, the foot in children appears to be flat or flexible and it is characterized by flattening of the arch under load, while its curvature is normal without load (Halabchi et al. 2013). Children with flat feet show higher activity within short muscles of the leg during walking. Since these muscles are the main stabilizers, more force is required to adequately secure the subtalar and Chopart's joints. This increased activity can also explain the pain that sometimes occurs with the flat feet (Carr et al. 2016). The joints become more mobile and, due to excessive valgosity, the center of force distribution moves to the inner edge of the foot. This leads to a shift of the talus head inferiorly and medially. The head of the talus together with the navicular bone fall on a surface and carry the weight of the whole body. Therefore, the contact of the lateral part of the longitudinal arch and the surface is missing during walking. This normally makes the inner ankle more prominent (Kampadji, 2009).

\section{Sensorimotor Stimulation}

This methodology, based on the Freeman's concept (1965) was developed by Vladimír Janda and Maria Vávrová (Janda, Vávrová 1992). The method of sensorimotor stimulation emphasizes the interconnection of afferent and efferent structures. The aim is therefore to achieve automatic reflex muscle activation so that there is no higher movement control and the movement is only performed under subcortical control. To facilitate the foot, the "short foot" exercise is used to activate the muscles of the foot, especially the m. quadratus plantae. The foot shortens in the longitudinal and transverse axes during exercise to shape the foot arch, resulting in a change in position of the joints and the distribution of pressure placed on them, thereby activating the proprioceptors of the foot (Kolár 2009). However, it is not only a procedure that achieves the automated muscle activity needed to eliminate muscle imbalance, but it can also affect the basic human movement patterns such as standing and walking. The methodology utilizes facilitation of skin receptors, as well as foot and neck muscles receptors (Pavlů 2003). The technique consists of a set of balancing exercises which can be performed in various postural positions. It proceeds from distal parts to proximal parts, i.e. it starts with foot correction by means of the "short foot" exercise. Sensorimotor stimulation also includes exercises with various aids such as spherical and cylindrical segments, balancing sandals or balancing balls (Koláŕ 2009).

\section{Objectives}

The aim of the research was to verify the effects of targeted corrective exercises on healthy foot development in preschool children. Navicular drop test and Podoscope plantogram analysis were performed.

\section{Methodology}

Preschoolers whose legal representatives had agreed to the research were included in the study. A sample parental consent form is provided in the Annex. Information about the possible neurological, orthopedic or traumatological findings on the lower extremities of the child has also been requested. Only the children without neurological, orthopedic and other congenital or acquired disorders of the lower extremities were included in the research. The research sample consisted of 210 children between the age group of $4-6$ years. The research was carried out in the period from September 2018 to March 2019. 
Qualitative research was conducted in kindergartens in Ruzomberok, Dolny Kubin and Zilina. The total number was 105 children, 51 (48.57\%) girls, and 54 (51.43\%) boys. The teachers in the kindergartens, where the experiment was carried out were acquainted with the principle of corrective exercises and the method of its application during the morning workout. As reported by Vittore and Caizzi (2010), a child's flexible flat foot either does not require treatment or symptomatic flat foot is treated with highquality orthopedic insoles to control the period of physiologically elevated joint laxity until the longitudinal arch stabilizes, which is at about the age of six. Using the navicular drop test, we evaluated the drop in the os naviculare while changing the load from sitting to standing posture. This test evaluates the fatigue level of the muscles that dynamically support the medial arch. Testing is first done while sitting. The patient has the lower limb set at $90^{\circ}$ in the hip, knee and ankle joint, the medial prominences of the os naviculare are marked with a fix and the height of this point from the ground is marked with a card. Subsequently, the patient stands up and the height of the os naviculare is again marked with the same card. If the distance between these points is bigger than $10 \mathrm{~mm}$, this is considered an abnormal change (Charlesworth, Johansen 2010). Most tests are based on the diagnosis of the longitudinal arch which shape is considered to be the most important for the proper functioning of the foot (Razeghi Batt 2002). Plantograms were created by using a diagnostic instrument PodoCam. We chose the frequently used and historically proven Chippaux-Smirak method for their analysis and determination of the foot arch indexes (Fig.1). The statistical analysis was performed using the Minitab 18 statistical program. The tables and graphs were presented in the Microsoft Excel program.

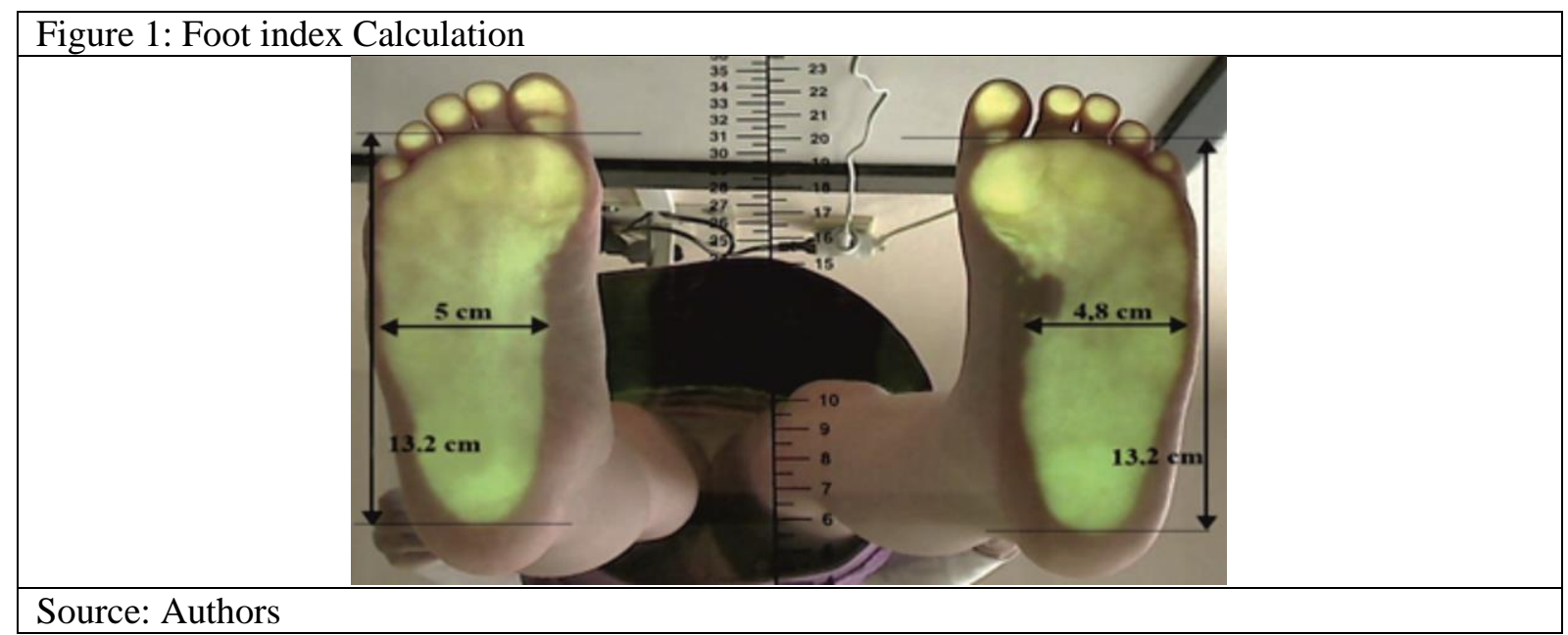

\section{Results}

The initial assessment of experimental group reported that $7.62 \%$ of preschool children had the physiological position of the arch on the right side. Slightly flat foot (1st degree) was reported in 29.52 $\%$ children, $35.24 \%$ children had medium flat foot (2nd degree) and $27.62 \%$ of the preschoolers had a strong flat foot (3rd degree). Based on the final assessment, the number of children with the physiological position of the longitudinal arch increased to $57.14 \%$ and the number of preschoolers of 3rd degree flat foot dropped significantly to $7.62 \%$. We evaluated the drop in the height of the plantar vault using the navicular drop test (Tab.1) on the left and right leg, the os naviculare when changing the load from sitting to standing before and after rehabilitation. After the intervention there was a significant increase in the foot arch on both legs. As to the experimental group, the physiological position of the arch on the right foot was found in $7.62 \%$ of preschoolers, slightly flat feet ( $1^{\text {st }}$ degree) in $29.52 \%$ of preschoolers, medium flat feet ( $2^{\text {nd }}$ degree) in $35.24 \%$ of preschoolers and strongly flat foot ( $3^{\text {rd }}$ degree) was in $27.62 \%$ of probands during baseline measurements. In the experimental group, the number of children with the physiological arch significantly increased to $57.14 \%$ and the number of $3^{\text {rd }}$ degree flat foot preschool children dropped to $7.62 \%$.

In experimental group, the value of the right foot drop test decreased in 95 probands. On the contrary, it increased only in 8 probands. Overall, there were differences in 103 children, only 8 remained unchanged. The results on the left leg are similar. The value decreased in 91 probands, increased in 10 children and did not change in 4 children. The median difference is -0.30 on the right leg and -0.25 on the left leg. The mean values are -0.285 and -0.419 . All values are less than zero. The P-values is 0.000 , 
so the differences are statistically very significant. We conclude that the drop test value on both legs in the experimental group decreased significantly. The normalized navicular drop test (NDT) noted asymptomatic flat feet in 105 probands. NDT ranged from 0.1 to 1.2 box graphs for right and left legs before and after physiotherapeutic intervention. The best parameter to characterize the central longitudinal arch structure was found to be the ratio of navicular height to foot length. It is accepted that the equality of normal children's legs and their age are inversely proportional. The leg length had a significant effect on the drop of the navicular bone. Improvement of flat feet was evaluated in preschoolers who moved from a higher to a lower degree of flat feet. Stagnation meant that the flat feet in preschoolers did not change during the final examination. The deterioration of the longitudinal arch of the foot was evaluated. We evaluated and reported the percentage differences in the table 2. Among the children in the experimental group the flatness in the right foot was dropped by 3 degrees in 3 children, it was dropped by 2 degrees in 28 children and by one degree in 51 children, while it was worsened in one child by one degree and by two degrees in 2 children. Overall, it decreased generally by one degree (median), which is a very significant difference ( $\mathrm{p}$-value is 0.000 ); the results were similar with the left foot in the experimental group. On the left leg, in 8 probands it was decreased by three degrees, in 30 children by two degrees, in 44 children by one degree, and in 20 children the degree did not differ, while it was deteriorated by one degree in 1 child and by two degree in 2 children.

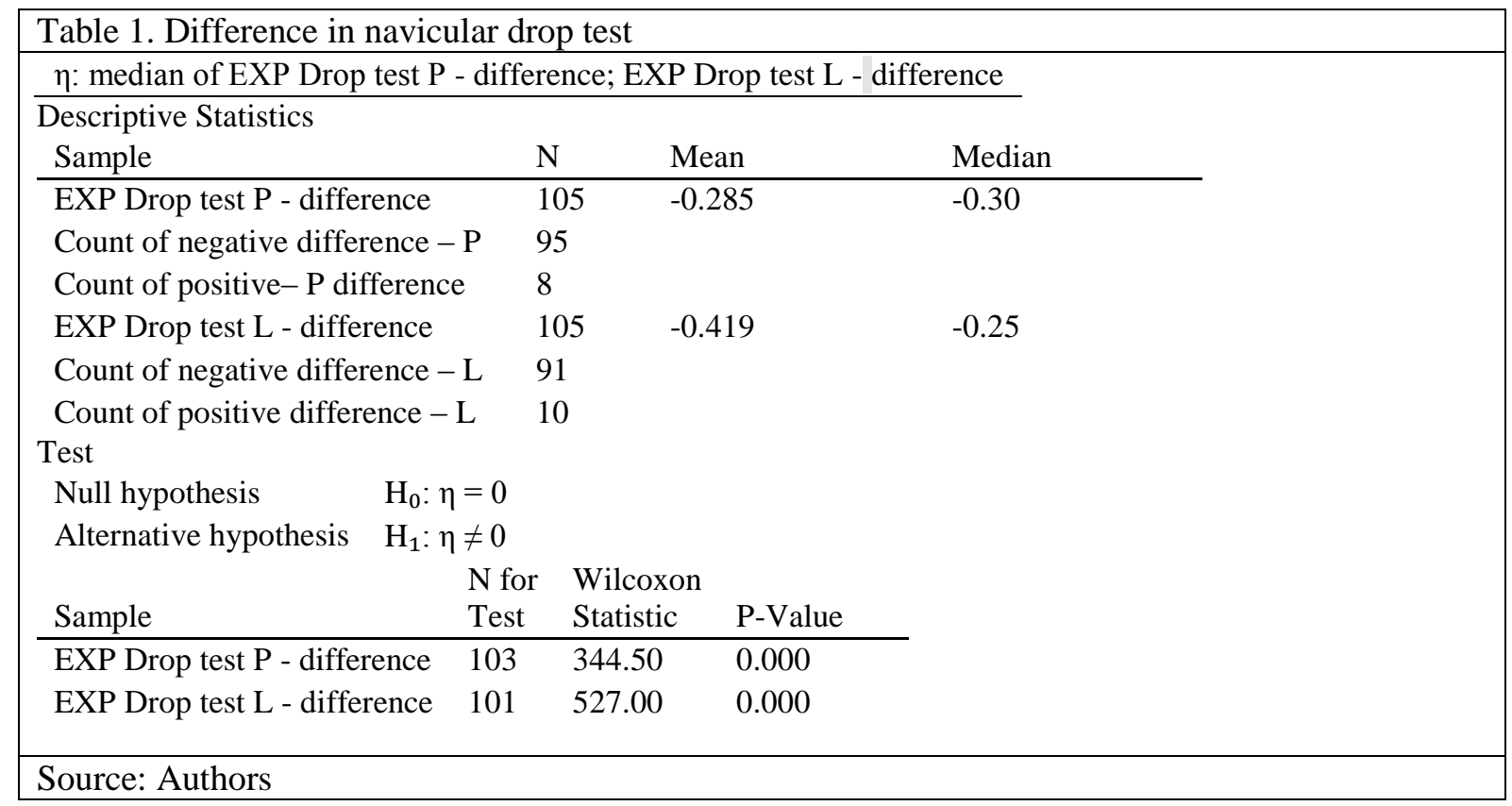

\begin{tabular}{|c|c|c|c|c|c|}
\hline \multicolumn{2}{|c|}{ EXP Flatness level, P - difference } & \multirow{2}{*}{$\begin{array}{r}\text { Count } \\
3 \\
\end{array}$} & Percent & & \\
\hline & -3 & & 2.8 & & \\
\hline & -2 & 28 & 26.6 & & \\
\hline & -1 & 51 & 48.5 & & \\
\hline & 0 & 20 & 19.0 & & \\
\hline & 1 & 1 & 0.9 & & \\
\hline & 2 & 2 & 1.9 & & \\
\hline & $\mathrm{N}=$ & 105 & & & \\
\hline Sample & & for Test & Median & Wilcoxon Statistic & P-Value \\
\hline EXP Flatness level, $\mathrm{P}$ - difference & & 85 & -1 & 161.50 & 0.000 \\
\hline
\end{tabular}




\section{Discussion}

Research suggests a positive impact of physiotherapeutic interventions on the flatness of feet of the children in the experimental group. The improvement and stagnation of flat feet are considered to be a beneficial effect of corrective excercises. Our study has shown that active exercise is the most effective in strengthening the muscles and maintaining the arch as well as the whole body posture. The role of sensorimotor exercise, which uses the so-called " short foot" training and the centralized position of all joints, should not be overlooked. In the recent years, kinesiology taping has emerged as a favorite therapy for physiotherapists. Research has shown that it has beneficial effects on reducing muscle tone and helps to activate the necessary muscles during exercise. Indeed, several studies have confirmed that the above mentioned measures successfully mitigate the negative effects caused by this deformity. Following these recommendations and regular exercise subsequently lead to the flat feet being successfully adjusted. But the question remains, until when a child's foot is perceived as a physiological phenomenon and from when the pathological concern develops? Evans and Rome (2011) stated that the arch development ceases at 4-6 years of age of a child. Singh et al. (2010) specified this period until the fifth year of a child's age. According to the authors, approximately 20 percent of children do not develop an arch at all, which always results in the formation of flat feet in future. During this phase, the ankle joint axis almost always gets a horizontal character, which is important for overall foot stabilization. At that time, the pronation of the talus and the anterior leg is often discontinued (Vařeka, Vařeková, 2009). Throughout human life, the leg grows in a synchronized way with the body, but not in proportion to the lower limb. After birth, growth is very fast and it slows down after a child's fifth year of life. In this period, the growth of the skeleton and some internal organs also slow down. The development of skeleton, most organs, bones and skin peaks at the age of 12 years for girls and 14 years for boys. Before reaching puberty, the length of the foot increases by an average of 0.9 centimeters per year. At the age of 10 , girls reach 90 percent of an adult female foot, while boys reach only 82 percent of an adult male foot. This finding also confirms that the boy's legs grow longer and more, even after reaching puberty (Singh et al. 2010).

\section{Conclusion}

Our study has shown that active exercise strengthening is the most effective in treating the flat feet. The affected muscles maintain the foot arch as well as the whole posture. The sensorimotor exercise, which uses the so-called "short foot" training and the centralized position of all joints were part of the treatment and we highly recommend it for the flat foot improvement. Kinesiology method has also appeared to be useful in our intervention.

\section{Ethical Approval}

All procedures performed in the studyinvolving human participants were in accordance with the ethical standards of the institutional and/or national research committee and with the Helsinki declaration and its later amendments or comparable ethical standards.

\section{Consent}

Informed consent was obtained from all individual participants included in the study.

\section{Disclosure}

This work was performed as part of the Ph.D. studies of authors in Catholic University in Ruzomberok, Slovakia.

\section{Data Availability}

The anonym examination results data used to support the findings of this study are available from the corresponding author upon request.

\section{References}

Carr, J. B., Yang, S., \& Lather, L. A. (2016). Pediatric Pes Planus: A State-of-the-Art Review. Pediatrics, 137(3). doi:10.1542/peds.2015-1230

Charlesworth, S.J., Johansen, S.M. (2010). Navicular Drop Test User Guide and Manual.

Evans, A. M., \& Rome, K. (2011). A Cochrane review of the evidence for non-surgical interventions for flexible pediatric flat feet. European journal of physical and rehabilitation medicine, 47(1), 69-89.

Freeman, M. A., Dean, M. R., \& Hanham, I. W. (1965). The etiology and prevention of functional instability of the foot. The Journal of bone and joint surgery. British volume, 47(4), 678-685.

Halabchi, F., Mazaheri, R., Mirshahi, M., \& Abbasian, L. (2013). Pediatric flexible flatfoot; clinical aspects and algorithmic approach. Iranian journal of pediatrics, 23(3), 247-260. 
Janda, V., Vávrová, M. Senzomotorická stimulace: Základy metodiky proprioceptivního cvičení. Rehabilitácia, 1992, roč. 25, č. 3, s. 14-34.

Kapandji, A. I. The physiology of the joints: annotated diagrams of the mechanics of the human joints. Volume 2, Lower limb. 5th ed. Edinburgh: Churchill Livingstone, 1987. ISBN 0-443-03618-7

Kolár̆, P. (2009). Rehabilitace v klinické praxi. Praha: Galén. ISBN 978-80-7262-657-1.

Moore, K. L., Agur, A. M., \& Dalley, A. F. (2019). Clinically oriented anatomy. Philadelphia: Wolters Kluwer Health. ISBN: 978-1451119459

Pavlů, D. (2003) Speciální fyzioterapeutické koncepty a metody I.: koncepty a metody spočívajicí převážně na neurofyziologické bázi 2nd edition. Brno: CERM. ISBN 80-7204-312-9

Razeghi, M., Batt, M. E. (2002). Foot type classification: a critical review of current methods. Gait \& posture, 15(3), 282291. https://doi.org/10.1016/s0966-6362(01)00151-5

Singh, A., Kumar, Srivastava, R., \& Gupta, O. (2010). Analysis of ankle alignment abnormalities as a risk factor for pediatric flexible flat foot. Internet Journal of Medical Update - EJOURNAL, 5(1). doi:10.4314/ijmu.v5i1.49290

Vařeka, I., Vařeková, R., (2009). Kineziology of foot. Olomouc: Palacky University in Olomouc. ISBN 978-80-244-2432-3.

Véle, F. Kineziologie. Přehled kineziologie a patokineziologie pro diagnostiku a terapii poruch pohybové soustavy. 2.

vydanie. 2006, s. 19. Praha: Triton, 2006. 375 s. ISBN: 80-7254-837-9.

Vitttore, D., Caizzi G. (2010). Il piedi piatto lasso dell'infanzia. Principi di biomeccanica e neurofisiologia per una metodica di trattamento conservativa con plantare e fisiokinesiterapia. Milano: Foggia da Timeo. ISBN: 9788886891981. 